\title{
Healthcare Utilization of Gynecological and Reproductive Morbidities: Role of Intra-Familial Relations and Empowerment among Women, Rural India
}

\author{
Mukesh Ravi Raushan ${ }^{1}$
}

\begin{abstract}
Maternal morbidity and mortality during pregnancy and childbirth is a serious concern in developing countries. The failure of women to discuss their reproductive health problems leads to less attention being given to healthcare for gynaecological and reproductive morbidities (GARMs). Intra-familial relations and empowerment specifically on GARMs may contribute to identifying determinants of healthcare in rural areas. Data from Primary Field Survey $(N=660)$ conducted during Feb-June, 2015 in 12 villages of Nalanda, Bihar, was accessed in order to identify the underlying determinants motivating women to seek advice or treatment for GARMs. The bivariate, logistic regression, and simultaneous equation modelling were used to achieve the objectives of the study. The GARMs related to female genital organs and menstrual cycle (56\%) followed by menstrual disorder (53\%), and prolapse (48\%) was found to be the most common among rural women in Bihar. By drawing attention to intra-familial relations and promoting women to interact on GARMs may reduce maternal morbidity or death, particularly in rural India.
\end{abstract}

Keywords Gynecological and reproductive morbidities; Empowerment; intra-familial relations; rural India

\section{Introduction}

Childbirth can lead to gynaecological and reproductive morbidities (GARMs) if not managed properly. The World Health Organization International Classification of Diseases (ICD-10) confirms morbidities such as female genital prolapse, menstruation disorder, pain and other conditions associated with female genital organs and menstrual cycle, pregnancy with abortive outcome, pregnancy and childbirth puerperium, maternal hypotension syndrome, complication of labour and delivery disorder venous puerperium disorder, infections of breast associated with childbirth, perinatal period disorder are common among women at disadvantaged sites. Earlier studies confirm that fewer morbidities have been studies but majority of them have wider scope of research especially in rural settings. The menstrual disorder, and pre-eclampsia are among those which has been studied. Studies on eclampsia indicate there are 2-3 cases per 10000 births in Europe while cases in developing countries tend to be 10-30 times more common than in high income countries. (Duley, 2009). Other studies showed that nutrition and body mass index (Fujiwara \& Nakata, 2010; Vyver, Steinegger, \& Katzman, 2008) show that complications such as polycystic ovary syndrome and infertility (Lambert-Messerlian et al., 2011), strenuous workout

\footnotetext{
1Senior Research Fellow, International Institute for Population Sciences, Mumbai, India Email: mrr.iips@gmail.com
} 
and exercise (Chang, Chen, Hsieh, \& Chiu, 2009; Earth \& Sthapit, 2002; Tegerstedt, Miedel, Mæhle-Schmidt, Nyrén, \& Hammarström, 2006) and presence of chronic morbidities (Adachi, 2008) are positively associated with GARMs among women. However, despite GARMs vastly affect maternal mortality and childbirth complications they have not attracted the attention of researchers. Complicating 2-8 percent of all pregnancies, pre-eclampsia, is a major contributor to maternal mortality worldwide (Khan, Wojdyla, Say, Gülmezoglu, \& Van Look, 2006; Steegers, von Dadelszen, Duvekot, \& Pijnenborg, 2010). The World Health Organization reports that as high as 18 million women aged 30-55 year report excessive menstrual bleeding (Goldrath, 1995). Askie et al. found that 10-15 percent of half million maternal deaths yearly are associated with pre-eclampsia and eclampsia, 99 percent of which are among the low-resource category (Askie, Duley, Henderson-Smart, \& Stewart, 2007).

Every day, approximately 830 women die of pregnancy and childbirth related causes mostly in developing countries, with over one third of all maternal deaths worldwide in 2015 being in Nigeria and India (WHO, 2015). The negative consequence associated with GARM include the healthcare cost in consuming expensive hormonal drugs and other laboratory tests (Houston, Abraham, Huang, \& D'Angelo, 2006), poor health (Adachi, 2008; Mathias, Kuppermann, Liberman, Lipschutz, \& Steege, 1996), and limitations on attendance from regular day to day life and missed activities (Houston et al., 2006; Kadir, Edlund, \& Von Mackensen, 2010). The studies on healthcare for GARMs include the medication of such disorders (Ganzevoort et al., 2005; Visser \& Wallenburg, 1995; Walker, Greer, \& Calder, 1983; Walraven et al., 2002) but mostly from developed region. The case in rural India is slightly exceptional and it becomes even more complicated in patriarchal society where despite the role of health care at home women cannot decide to seek advice/treatment for her health (Dyson \& Moore, 1983). In this case what brings women to healthcare provider need to be focused particularly in rural setting in rural Bihar, India? Till the date, there is no such study exist dealing the GARMs especially for the study population of Bihar, India. The objective of the paper is to study determinants promoting women for advice or treatment seeking for gynecological and reproductive morbidities (GARMs). This study tries to contribute in existing literature that intra-familial relations (IFR), and women's empowerment for gynecological and reproductive morbidities (WEGARMs) play a significant role in healthcare for GARMs among rural women Nalanda, Bihar.

\section{Data and Methods}

The data comes from primary field survey. The sampled villages were selected from Census 2011 with the probability of selection being proportional to number of households in village at district (Census, 2011a, 2011b) followed by complete house listing in selected villages. The district, of Nalanda in Bihar was selected based on its having the highest prevalence of any type of gynecological and reproductive morbidities (IIPS, 2010) and low female literacy levels (Census, 2011b). The survey was conducted during Feb-May 2015 using pre-structured and pretested schedule $(n=660)$. A complete listing of women who are pregnant for 3 to 4 months or having at least one child in last five years prior to survey. At the final stage, selecting respondent from house list and minimizing intra-household correlation only one youngest currently married woman from each household and 55 women from each village, in total 660 women were selected using systematic random sampling from 12 villages, in Nalanda district, Bihar, India. The information on gynecological and reproductive morbidities, socio-economic and demography 
characteristics was collected through face-to-face interview using a pretested structured bilingual schedule after obtaining informed written consent. The ethical clearance certificate came from the Students Research Ethics Committee (SREC) of the institute. The survey was supplemented with information on the household, birth history, advice/treatment seeking behavior for GARM, and availability of money among women. The data entry was done using CSPro 6.3 (Pro \& Pro, 2016) and analyzed using STATA 13 (StataCorp, 2014).

\section{Methods}

The bivariate, multivariate binary logistic regression technique (Pampel, 2000) was used to predict the healthcare utilization among women experiencing the gynecological and reproductive morbidities. To understand the endogeneity of the intra-familial relations and women empowerment for gynecological and reproductive morbidities simultaneous equation modelling (Greene, 1993) was used. Chi-square test was also used to check the association between women's characteristics.

\section{Dependent variable}

The dependent variable is treatment/treatment seeking for GARMs. It was measured by a categorical variable, whether women sought treatment or advice for her GARMs from any healthcare personnel including ASHA, ANM, nurse or doctors of primary healthcare center $(\mathrm{PHC})$, and private/government hospitals $(1=$ yes; otherwise $=0)$.

\section{Independent variables}

Index of empowerment for gynecological and reproductive morbidities: The index of women empowerment for gynecological and reproductive morbidities was computed using binary information on whether permission seeking is problematic on 3- point Likert scale. Whether for women the seeking advice/treatment was a big problem $(=1)$, small problem $(=2)$ or not at all $(=3)$. The information on women empowerment for gynecological and reproductive morbidities was collected through eleven types of questions such as (1) as getting permission to go; (2) getting money needed for treatment; (3) distance to the health facility; (4) having to take transport; (5) finding someone to go with you; (6) concern that there may not be a female health provider; (7) concern that there may not be any health provider; (8) concern that there may be no drugs available; (9) any previous bad experience; (10) location of health care facility/provider; (11) household duties. The Cronbach alpha for the index was measured as 0.735 . Based on the mean value the index $(\mu=19.5)$ and categorized into two (low = below mean; and high = above mean).

Index of intra-familial relations: To access women's solidarity of relation with household members and frequency of interaction, a new variable was generated. The interaction with family member among woman was measured by eight types of social domain. These social domains include (1) religious, (2) money for daily needs, (3) surrounding conditions, (4) property, (5) maintaining public relation through reciprocity in terms of exchange of gifts, (6) visit to relative, (7) general health and (8) own (woman's) health. Therefore, intra-familial relations among women were computed using eight questions on Likert scale during last six months prior to survey. It was ensured (by asking during interview) that whether discussion in such discussion were not lead to bitterness in familial relation. The information was collected using questions such as "do you discuss on the domain with your family members?" and if yes, then "what is the frequency of discussion" (like $0=$ never; $1=$ Once in a month; $2=2 / 3$ times in a month; $3=4 / 5$ times or once in a 
week; $4=2 / 3$ times in a week or daily). The Cronbach alpha for the index is 0.91 . Based on the mean value the index $(\mu=17.2)$ was categorized into two (low = below mean; and high $=$ above mean). The information on education $(0=$ illiterate, $1=$ primary, and $2=$ secondary and higher women's work status $(0=$ housewife i.e. no paid work/housewife, $1=$ agricultural labor i.e. agricultural related activity, $2=\mathrm{HW}$ plus work i.e. contribute in husband's business along with her own role as housewife); parity $(0=1 / 2,1=3$, and $2=3+)$; sanitation facility $(0=$ non-improved toilet, $1=$ improved toilet), religion $(0=\mathrm{Hindu}, 1=$ Muslim $)$ and caste $(0=$ scheduled caste $/$ tribe, $1=$ Other backward classes, $2=$ others) were also assessed.

\section{Background}

\section{Study Population: Nalanda, Bihar}

The demographic scenario of Nalanda, Bihar is not very satisfactory (Table 1). With lower female literacy, seems to account for low marriageable age i.e. 23 percent marrying below 18 years. The infant mortality rate (42) and maternal mortality rate (23) is amongst the highest for India (RGI, 2013, 2016). Despite the 10 percent per annum of net state domestic product (NSDP) records show the low absolute income - in tenth five-year plan period - as its per capita income at constant prices is still the lowest in the country. Furthermore, a high intra-state disparity made the incidence of poverty most prominent and therefore, the state lies near the bottom of the HDI rank (GOI, 2011). As the third most populous state, Bihar has a gender ratio of 916 (females per 1000 males) and 4.9 million of female shares 9 percent of total Indian population (Census, 2011).

Table 1: Area and demographic profile of the district Nalanda, Bihar, India

\begin{tabular}{|c|c|c|}
\hline Indicators & Nalanda & Bihar \\
\hline Area (sq. Km.) & $2,355^{\mathrm{a}}$ & 94,163 \\
\hline No. of $\mathrm{HH}$ & $477,529 a$ & $18,867,444$ \\
\hline \multicolumn{3}{|l|}{ Population } \\
\hline Male & $1,497,060$ & $54,278,157$ \\
\hline Female & $1,380,593$ & $49,821,295$ \\
\hline \multicolumn{3}{|l|}{ Sex Ratio } \\
\hline Overall sex ratio & $921^{\mathrm{a}}$ & 916 \\
\hline Child sex ratio & $959 b$ & 935 \\
\hline Percentage of scheduled caste & $21.1^{\mathrm{a}}$ & 15.9 \\
\hline Percentage of scheduled tribe & $0.0^{\mathrm{a}}$ & 1.3 \\
\hline Percentage of urban population & 15.9 & 11.3 \\
\hline Decadal Growth Rate (2001-2011) & 21.3 & 25.4 \\
\hline Population Density (Pers./sq. Km.) & 1,222 & 1,106 \\
\hline$\%$ of girls marrying below 18 years & $22.5^{\mathrm{b}}$ & $13.8^{b}$ \\
\hline$\%$ of boys marrying below 21 years & $29.7 \mathrm{~b}$ & $20.6^{b}$ \\
\hline$\%$ using any family planning method & $35^{b}$ & $41.2^{\mathrm{b}}$ \\
\hline Mother availed financial assistance for delivery under JSY (\%) & $47.6^{\mathrm{b}}$ & $40.9^{b}$ \\
\hline \multicolumn{3}{|l|}{ Literacy Rate } \\
\hline Male & 77.1 & 73.4 \\
\hline Female & 54.7 & 53.3 \\
\hline
\end{tabular}

Data Source: Sex Ratio: females per 1000 males. Primary Census Abstract, Table A-5, Series 11, Bihar, Census of India 2011. New Delhi: Directorate of Census Operations, Registrar General \& Census Commissioner, India.

a District Census Handbook, Series- 11, Part XII-B, Village and Town Wise Primary Census Abstract, Nalanda, Bihar, Census of India, 2011. New Delhi: Directorate of Census Operations, Registrar General \& Census Commissioner, India.

b Annual Health Survey 2012-13 Factsheet, Bihar. New Delhi: Office of the Registrar General \& Census Commissioner, Ministry of Home Affairs, Government of India, India. 
The district of Nalanda has amongst the lowest female literacy rates (54.7\%) in India (Census, 2011a). The district level household and facility survey shows that 56 percent of the women in Nalanda have reproductive problems during pregnancy (IIPS, 2010) and 23 percent of girls marry before 18 years (ORGI, 2013). The mean age of women in the study was 25 years with five years of schooling. The study population comprised 8 percent Muslim and 61 percent from the scheduled caste (SC) and 14 percent from other backward caste (OBC). The scheduled castes (SCs) and other backward caste $(\mathrm{OBC})$ are the official designations given to various groups of who have been historically marginalized, recognized in the Constitution of India.

\section{Level of gynecological and reproductive morbidities in Nalanda}

The findings show that most common was pain and other conditions associated with female genital organs and menstrual cycle was common (56\%), followed by menstruation disorder (54\%) and pregnancy and childbirth the puerperium (53\%). However, the GARMs was lowest for perinatal period disorder (14\%) to pain and other conditions associated with female genital organs and menstrual cycle $(56 \%)$.

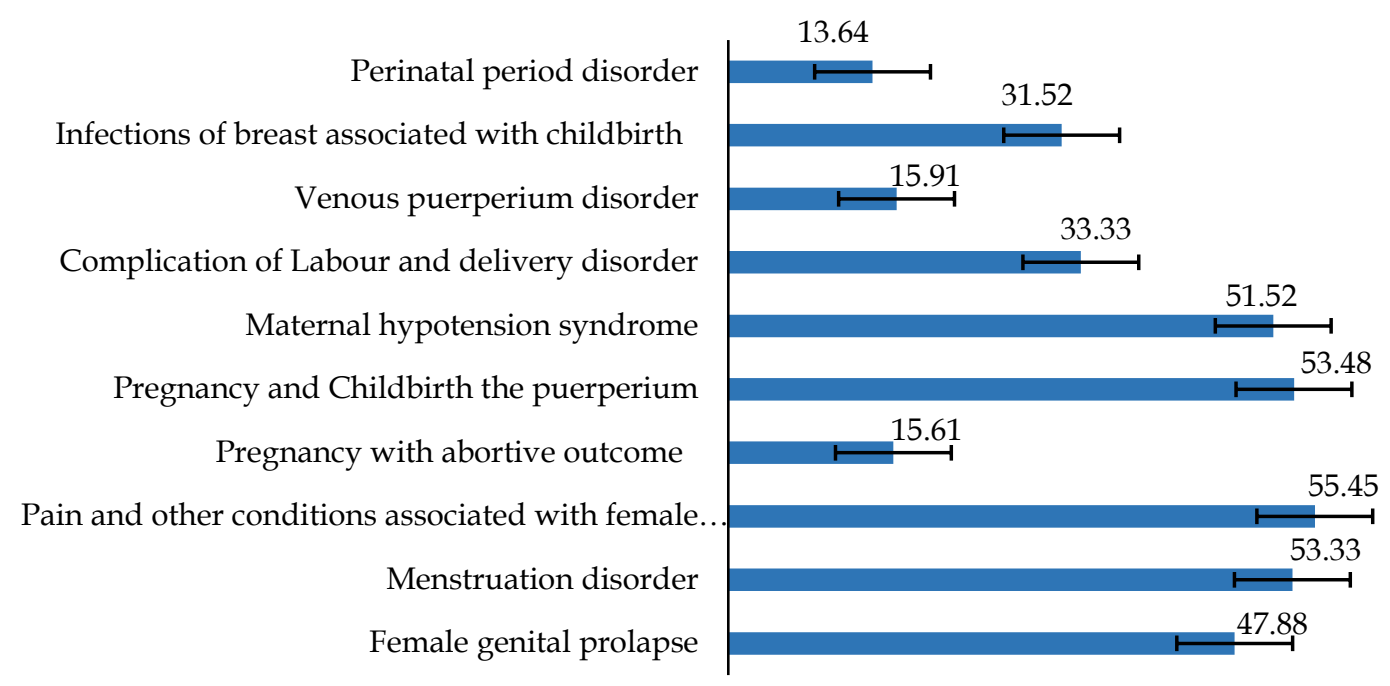

Figure 1: Percentage of gynecological and reproductive problems among women (15-49), 2015

About 52 percent women found to experience maternal hypotension syndrome. In Figure 1, the GARMs such as menstruation disorder, pain and other conditions associated with female genital organs and menstrual cycle, pregnancy and childbirth the puerperium, maternal hypotension syndrome were common and about two-fifth of these women were found to experience problems $(p<0.05)$.

\section{Women empowerment for gynecological and reproductive morbidities (WEGARMs)}

Assessing individual characteristics such as empowerment among women in the context of GARMs and intra-familial relations (IFR) can help in measuring individual characteristics and those related to health. The study found that lower aged women were less empowered for GARMs compared to those who are older. In this context, Table 2 shows that 26 percent women 
aged 15-24 years were highly empowered compared to 54 percent women aged 25-34 years in Nalanda. Earlier studies had reported similar findings (Kishor \& Subaiya, 2008). The women of lower parity were reported to be highly empowered compared to those with higher parity. About 61 percent women with parity of one/two compared to 21 percent with three plus parity was found to possess high empowerment for GARMs in Nalanda, Bihar. The association of intrafamilial relations and WEGARMs reveals that women with higher intra-familial relations were more likely to be more empowered on reproductive health matters. About 57 percent women with high IFR were more empowered compared to 36 percent women with low IFR. Decision making on issues related to GARMs were less likely to be problematic if the women's intrafamilial relations were higher $(p<0.001)$.

\section{Intra-familial relations among women in Nalanda, Bihar}

The study found that only 37 percent women had high intra-familial relations (Table 2). Characteristics such as age of women, parity, husband's work, women's work, and educational attainment were found to be significant factors $(p<0.01)$. The IFR and women's education was found to be significantly associated $(p<0.001)$ and intra-familial interaction was found higher among illiterate women. This study found that household economic status also contributes to better intra-familial relations. For instance, among women with high intra-familial relations, about 61 percent women were found richer compared to 20 percent women with low wealth status. However, the woman's educational attainment was found negatively associated with intra-familial relations $(p<0.001)$. In other words, women with less education were more interactive in nature on given social dimension. It is evident that about 53 percent illiterate women were found to be interacting compared to 25 percent for those with primary and secondary education (Table 2). 
Table 2: Percentage of women with high empowerment on gynecological and reproductive morbidity (WEGARMs) and intra-familial relation (IFR) in Nalanda, rural Bihar, India

\begin{tabular}{llll}
\hline \multicolumn{1}{c}{ Women's } & WEGARMs & \multicolumn{1}{c}{ IFI } & N \\
\hline Age group & $71.46^{* * *}(2)$ & $14.046^{* * *}(2)$ & \\
$15-24$ & 26.0 & 33.6 & 461 \\
$25-34$ & 54.1 & 41.0 & 159 \\
$35-49$ & - & 46.4 & 40 \\
Parity & $65.85^{* * *}(2)$ & $14.979^{* * *}(2)$ & \\
One/Two & 60.8 & 33.3 & 243 \\
Three & 44.7 & 32.5 & 232 \\
Four and more & 21.3 & 49.2 & 185 \\
Husband Work & $68.18^{* * *}(1)$ & $14.014^{* * *}(1)$ & \\
Agricultural Labor & 63.6 & 28.8 & 261 \\
Others & 31.1 & 43.2 & 399 \\
Women's Work & $5.99^{*}(2)$ & $70.18^{* * *}(2)$ & \\
Housewife & 39.5 & 30.3 & 340 \\
Agricultural Labor & 48.7 & 28.3 & 187 \\
HW plus work & 49.2 & 31.1 & 133 \\
Women's Education & $122.23^{* * *}(2)$ & $57.251^{* * *}(2)$ & \\
Illiterate & 26.7 & 53.4 & 295 \\
Primary & 26.7 & 24.8 & 232 \\
Secondary & 70.3 & 24.7 & 133 \\
IFI & $28.747^{* * *}(1)$ & & \\
Low & 36.1 & & 413 \\
High & 57.5 & 37.4 & 247 \\
\hline Total & 44.1 & & 660 \\
\hline
\end{tabular}

\begin{tabular}{|c|c|c|c|}
\hline $\begin{array}{c}\text { Women's } \\
\text { Characteristics }\end{array}$ & WEGARMs & IFI & $\mathbf{N}$ \\
\hline Wealth Status & $4.82(2)$ & $87.80^{* * *}(2)$ & \\
\hline Low & 38.8 & 19.5 & 238 \\
\hline Middle & 45.8 & 26.4 & 292 \\
\hline High & 50.0 & 60.8 & 130 \\
\hline Source of water & $96.58^{* * *}(2)$ & $79.15^{* * *}(2)$ & \\
\hline Tube well/borehole & 57.1 & 33.2 & 118 \\
\hline Standpipe/Public & 43.3 & 75.0 & 135 \\
\hline Unprotected Well & 11.0 & 23.2 & 407 \\
\hline Sanitation facility & $26.18^{* * *}(1)$ & $0.50(1)$ & \\
\hline Improved & 16.9 & 33.8 & 78 \\
\hline Non-improved & 47.7 & 37.9 & 582 \\
\hline Religion & $22.58^{* * *}(1)$ & $4.87(1)$ & \\
\hline Hindu & 41.3 & 38.7 & 604 \\
\hline Muslim & 74.6 & 23.6 & 56 \\
\hline Caste & $40.11^{* * *}(2)$ & $5.84(2)$ & \\
\hline SC & 49.8 & 36.3 & 400 \\
\hline OBC & 14.0 & 48.4 & 94 \\
\hline Other & 47.3 & 33.9 & 166 \\
\hline Total & 44.1 & 37.4 & 660 \\
\hline $\begin{array}{l}\text { Note: Degrees of freedc } \\
* * *: p \leq 0.001 ; * *: p \leq 0.0 \\
\text { backward caste (OBC) } \\
\text { historically marginaliz }\end{array}$ & $\begin{array}{l}\text { arenthesis; } \\
0.05 ; \text { The schedul } \\
\text { official designatio } \\
\text { le, recognized in }\end{array}$ & $\begin{array}{l}\text { (SCs) and O } \\
n \text { to various g } \\
\text { stitution of In }\end{array}$ & \\
\hline
\end{tabular}




\section{Determinants of Women empowerment on gynecological and reproductive morbidities (WEGARMs) and Intra-familial relation (IFR)}

The Table 3 represents the coefficient of logistic regression for dependent variable IFR and WEGARMs which serves as a preliminary predictor for simultaneous equation modelling. Age of women, parity, husband's work status, women's work status, women's education, socio-economic status, and caste were reported to be significantly associated with IFR and WEGARMs. Controlling women's individual level characteristics, the odds of IFR was found significantly higher for those with high WEGARMs (OR: 6.53, $p<0.001$ ), meaning the probability that intra-familial relations is high, about seven times as likely as the value of the WEGARMs increased by one unit from low to high. The probability that a WEGARMs is high was reported to be three times as likely as the familial relations increased by one unit from low to high (OR: $3.48, p<0.001)$. The probability of intra-familial relation among women aged 35-49 years and parity three were more pronounced than younger woman. The probability that women had high interaction or high intra-familial relations were four times as likely as their work status change from housewife to working plus housewife. In addition, the odds of WEGARMs was significantly higher $(\mathrm{OR}=1.59, p<0.05)$ in the case of women who participated in their husband's job while at the same time playing the role of housewife than women who were only housewives. The logit model supports the bivariate result that odds of high intrafamilial relation among secondary educated women were about 0.08 ( $92 \%$ lesser) than that of illiterate women. On the other hand, the odds of women with secondary or primary education was 4.5 and 2.6 times that of illiterate women.

The odds of familial relation being high was greater among women with high empowerment on reproductive health (OR: 3.2, $p<0.001$ ). The odds of being high WEGARMs was found 3.83 for women whose familial relation was high. The odds of intra-familial relations among richer women was significantly higher compared to poorer women (OR: 1.2, $p<0.001)$. Similarly, caste belongingness was also observed to be significantly associated with the IFR and WEGARM. The odds of IFR was found to be higher among other backward caste women than the scheduled caste (OR: 6.03, $p<0.001$ ).

Table 3: The odds of intra-familial relation (IFR) and women empowerment for gynecological and reproductive morbidities (WEGARMs) among women in Nalanda, rural Bihar, India

\begin{tabular}{|c|c|c|c|c|c|}
\hline $\begin{array}{l}\text { Women's Individual } \\
\text { Level Characteristics }\end{array}$ & IFR & WEGARMs & $\begin{array}{l}\text { Women's Household } \\
\text { Level Characteristics }\end{array}$ & IFR & WEGARMs \\
\hline WEGARMs & & & WEGARMs & & \\
\hline Low (a) & & & Low (a) & & \\
\hline High & $6.531^{* * *}$ & NA & High & $3.2^{* * *}$ & NA \\
\hline IFR & & & IFR & & \\
\hline Low (a) & & & Low (a) & & \\
\hline High & NA & $3.482^{* * *}$ & High & NA & $3.83^{* * *}$ \\
\hline Age group & & & Wealth Status & & \\
\hline $15-24$ (a) & & & $\operatorname{Low}^{(a)}$ & & \\
\hline 25-34 & $3.043^{* *}$ & $0.156^{* * *}$ & Middle & $1.092^{* * *}$ & 0.714 \\
\hline $35-49$ & $3.445^{*}$ & - & High & $1.217^{* * *}$ & 0.932 \\
\hline Parity & & & Source of water & & \\
\hline One/Two (a) & & & Tube well/borehole (a) & & \\
\hline Three & $1.946^{*}$ & $0.351^{*}$ & Standpipe/Public & $2.332^{*}$ & $0.134^{* * *}$ \\
\hline Four and more & 1.364 & $0.184^{* * *}$ & Unprotected Well & $0.3^{* *}$ & $0.035^{* * *}$ \\
\hline Husband Work & & & Sanitation facility & & \\
\hline Agricultural Labor (a) & & & Improved (a) & & \\
\hline Others & $2.018^{* *}$ & $0.304^{* * *}$ & Non-improved & 1.76 & $3.182^{* *}$ \\
\hline
\end{tabular}


Table 3 (continued)

\begin{tabular}{lcc}
\hline $\begin{array}{l}\text { Women's Individual } \\
\text { Level Characteristics }\end{array}$ & IFR & WEGARMs \\
\hline $\begin{array}{l}\text { Women's Work } \\
\text { Housewife (a) }\end{array}$ & & \\
Agricultural Labor & 0.983 & 1.019 \\
HW plus work & $4.015^{* * *}$ & $1.594^{*}$ \\
Women's Education & & \\
Illiterate (a) & & \\
Primary & $0.167^{* * *}$ & $2.566^{* * *}$ \\
Secondary \& high & $0.077^{* * *}$ & $4.513^{* * *}$ \\
\hline Constant & $0.123^{* * *}$ & $0.316^{*}$ \\
N & 660 & 620 \\
log likelihood_null & -436.38 & -428.586 \\
log likelihood_full & -316.884 & -267.822 \\
BIC & 711.675 & 606.37 \\
LR chi ${ }^{2}$ (11) & 238.98 & 321.53 \\
Prob. $>$ Chi ${ }^{2}$ & 0.001 & 0.001 \\
\hline
\end{tabular}

\begin{tabular}{lcc}
\hline $\begin{array}{l}\text { Women's Household } \\
\text { Level Characteristics }\end{array}$ & IFR & WEGARMs \\
\hline $\begin{array}{l}\text { Religion } \\
\text { Hindu (a) }\end{array}$ & & \\
$\begin{array}{l}\text { Muslim } \\
\text { Caste }\end{array}$ & 0.692 & 1.935 \\
SC (a) & & \\
OBC & $6.032^{* * *}$ & $0.201^{* * *}$ \\
Other & 1.154 & 0.924 \\
& & \\
\hline Constant & $0.361^{*}$ & $0.176^{* * *}$ \\
N & 660 & 660 \\
log likelihood_null & -436.38 & -452.857 \\
log likelihood_full & -337.623 & -318.283 \\
BIC & 753.153 & 714.47 \\
LR chi2 (11) & 197.5 & 269.15 \\
Prob. > Chi 2 & 0.001 & 0.001 \\
\hline
\end{tabular}

Note: NA: indicates not applicable; (a): Reference Category.

${ }^{* * *}: p \leq 0.001 ;{ }^{* *}: p \leq 0.01 ;{ }^{*}: p \leq 0.05$; The scheduled castes (SCs) and Other backward caste (OBC) are the official designations given to various groups of historically marginalized people, recognized in the Constitution of India.

\section{Interdependency of Women empowerment (WEGARMs) and Intra-familial relation (IFR) on gynecological and reproductive morbidities in rural Bihar}

The Wald test confirms the simultaneity of the WEGARMs and IFR in the context of GARMs among women in rural setting. The two-stage probit least squares (2SPLS) model show that WEGARMs was positively associated with IFR $(p<0.001)$ (Table 4$)$. The IFR decreases as the permission seeking among women for their GARMs tend to be a bigger problem. On average, WEGARMs tend to result in 0.65 percent increase in intra-familial relation. In other words, the women experiencing GARMs was found to possess high IFR if women's experience for permission seeking were found to be less problematic. The WEGARMs tend to increase 0.65 percent in intra-familial relations while 1.18 percent by education increases particularly secondary education. The effect of empowerment on intra-familial relation was found to be lower than women's education $(p<0.01)$. Similarly, education, socio-economic status, water and sanitation facilities were found to be positively associated with IFR in Nalanda, rural Bihar. It is evident that primary education $(\beta=1.74, p<0.05)$ had greater impact than secondary and higher level educational $(\beta=1.12, p<0.05)$. However, factors such as higher parity, women's work status as housewife, and using water from unprotected well negatively shaped the percentage of intra-familial relations among women in the household. For instance, housewives record a 0.92 percent decrease in familial relation $(p<0.001)$.

The effect of intra-familial relations on WEGARMs was found to be positively associated $(p<0.01)$. In other words, the women participating in intra-familial relations tend to have less problems in getting permission to access healthcare for GARMs by 0.16 percent. The study found that women controlling their parity to one/two were found to be empowered in context of GARMs $(\beta=0.69, p<0.05)$ than those who faced problems in getting permission. This study supports that the view that education increases empowerment by 1.19 percent and 2.19 percent for those with primary education and secondary education respectively, thus increasing in WEGARMs $(p<0.01)$. 
Table 4: Result of Two-Stage Probit Least Squares (2SPLS) Model for intra-familial relations (IFR) and women empowerment for gynecological and reproductive morbidities (WEGARMs) among women, Nalanda, rural Bihar, India

\begin{tabular}{|c|c|c|c|c|c|c|}
\hline \multirow{2}{*}{ Variable } & \multicolumn{3}{|l|}{ IFR } & \multicolumn{3}{|c|}{ WEGARMs } \\
\hline & Est. & $S E$ & Z & Est. & $S E$ & Z \\
\hline WEGARMs & $0.65^{\star \star \star}$ & 0.1863 & 3.49 & NA & & \\
\hline IFR & NA & & & $0.159^{* *}$ & 0.05 & 3.18 \\
\hline Respondent age & & & & & & \\
\hline $15-24$ (a) & & & & & & \\
\hline $25+$ & $0.665^{*}$ & 0.3068 & 2.17 & 0.694 & 0.4316 & 1.61 \\
\hline Parity & & & & & & \\
\hline One/Two & -0.082 & 0.1885 & -0.43 & $0.687^{*}$ & 0.2748 & 2.5 \\
\hline Three(a) & & & & & & \\
\hline Four and more & $-1.859 * *$ & 0.556 & -3.34 & $-1.468^{* *}$ & 0.5116 & -2.87 \\
\hline Women Education & & & & & & \\
\hline Illiterate ${ }^{(a)}$ & & & & & & \\
\hline Primary & $1.739^{*}$ & 0.8196 & 2.12 & $1.189 * *$ & 0.4019 & 2.96 \\
\hline Secondary \& High. & $1.188^{*}$ & 0.5542 & 2.14 & $2.189 * * *$ & 0.3243 & 6.75 \\
\hline Women's Work Status & & & & & & \\
\hline Housewife & $-0.92 * * *$ & 0.2226 & -4.13 & $-1.441^{* *}$ & 0.4639 & -3.11 \\
\hline Agricultural Lab. & -0.209 & 0.3215 & -0.65 & $-0.834^{*}$ & 0.4012 & -2.08 \\
\hline HW plus work & & & & & & \\
\hline Wealth Status & & & & & & \\
\hline $\operatorname{Low}^{(a)}$ & & & & & & \\
\hline Middle & $3.172^{* * *}$ & 0.6942 & 4.57 & $2.557^{* * *}$ & 0.4287 & 5.96 \\
\hline High & $4.771^{* * *}$ & 0.938 & 5.09 & $4.173^{* * *}$ & 0.6994 & 5.97 \\
\hline Water Facility & & & & & & \\
\hline Tube well/Borehole & $1.397^{* * *}$ & 0.3479 & 4.02 & $1.513^{* * *}$ & 0.3776 & 4.01 \\
\hline Standpipe/public(a) & & & & & & \\
\hline Unprotected Well & $-1.973^{* * *}$ & 0.3807 & -5.18 & $-2.213^{* * *}$ & 0.5333 & -4.15 \\
\hline Toilet Facility & & & & & & \\
\hline Non-improved(a) & & & & & & \\
\hline Improved & $-0.797^{*}$ & 0.3194 & -2.5 & $-1.642^{* *}$ & 0.5447 & -3.01 \\
\hline Caste & & & & & & \\
\hline Scheduled Caste & & & & 0.86 & 0.4674 & 1.84 \\
\hline $\mathrm{OBC}^{(\mathrm{a})}$ & & & & & & \\
\hline Others & & & & 0.63 & 0.481 & 1.31 \\
\hline Religion & & & & & & \\
\hline Hindu & & & & -0.284 & 0.3132 & -0.91 \\
\hline Muslim(a) & & & & & & \\
\hline _constant & $13.34^{* * *}$ & 3.5313 & 3.78 & 2.925 & 1.6166 & 1.81 \\
\hline$N$ & 660 & & & 660 & & \\
\hline LR Chi2 (df.) & $239.07(15)$ & & & $381.48(18)$ & & \\
\hline Prob. > chi 2 & 0.001 & & & 0.001 & & \\
\hline Pseudo R2 & 0.274 & & & 0.421 & & \\
\hline log likelihood_null & -436.376 & & & -425.857 & & \\
\hline log likelihood_full & -316.843 & & & -262.117 & & \\
\hline Wald Test $\left(C h i^{2}, d f ., p\right)$ & $0.06(1, p=0.813)$ & & & $0.04(1, p=0.847)$ & & \\
\hline
\end{tabular}

Note: Wald Test: Wald Test of exogeneity; (a): Reference Category; ${ }^{* * *}: p \leq 0.001 ;{ }^{* *}: p \leq 0.01 ;{ }^{*}: p \leq 0.05$

\section{Healthcare for gynecological and reproductive morbidities in rural setting, Bihar, India}

The literature on healthcare utilization for gynecological and reproductive morbidities are not available for Nalanda, Bihar. Treatment for gynecological and reproductive morbidities is lower due to factors such as shame, humiliation (Dixon-Mueller and Wasserheit, 1991). The issue of advice taking and treatment seeking are considered as healthcare in this study. The assessment of IFR and WEGARMs indicates that probability of healthcare utilization for 
GARMs was about seven times as likely as the value of IFR increased by one unit from low to high (Table 5). While the probability of healthcare utilization was about 1.5 times as likely as the value of WEGARMs increased from low to high (Model 1). Women aged 25-34 years were more likely to seek advice or treatment for the GARMs (OR: 7.23, $p<0.01)$ compared to women aged 15-24 years. Individual level characteristics such as lower parity, and women's education were found significantly positively associated with GARMs healthcare. The odds of healthcare among women with parity three (OR: $0.13, p<0.01)$ and four and more (OR: 0.01, $p<0.001)$ were significantly lower than the women with parity one/two. This study found that women with higher education (OR: 2.07, $p<0.001$ ) were more likely to seek advice or treatment for their gynecological morbidity than illiterate women. The odds of healthcare utilization for GARMs among women contributing in her husband's business along with her own role of housewife were lower than housewife. The assessment of interaction variable of IFR and WEGARMs show that likelihood of GARMs healthcare were higher among women poses high IFR and WEGARMs (OR: 8.77, $p<0.01)$, controlling other women's individual and household level factors (Model 3).

Table 5: Odds of health care utilization for gynecological and reproductive morbidities among women, Nalanda, rural Bihar, India

\begin{tabular}{|c|c|c|c|}
\hline Covariates & Model 1 & Model 2 & Model 3 \\
\hline \multicolumn{4}{|l|}{ IFR } \\
\hline \multicolumn{4}{|l|}{ Low (a) } \\
\hline Higher & $6.524^{* * *}$ & & \\
\hline \multicolumn{4}{|l|}{ WEGARMs } \\
\hline \multicolumn{4}{|l|}{$\operatorname{Low}^{(a)}$} \\
\hline Higher & $1.546^{* * *}$ & & \\
\hline \multicolumn{4}{|l|}{ IFR \& WEGARMs } \\
\hline \multicolumn{4}{|l|}{ Both Low ${ }^{(a)}$} \\
\hline at least one high & & & 0.841 \\
\hline Both High & & & $8.769^{* *}$ \\
\hline \multicolumn{4}{|l|}{ Age group } \\
\hline \multicolumn{4}{|l|}{$15-24^{(a)}$} \\
\hline $25-34$ & & $7.232^{* *}$ & $3.327^{*}$ \\
\hline $35-49$ & & 0.427 & 0.381 \\
\hline \multicolumn{4}{|l|}{ Parity } \\
\hline \multicolumn{4}{|l|}{ One/Two(a) } \\
\hline Three & & $0.128^{* *}$ & $0.168^{* *}$ \\
\hline Four and more & & $0.014^{* *}$ & $0.007^{* *}$ \\
\hline \multicolumn{4}{|l|}{ Women's Work } \\
\hline \multicolumn{4}{|l|}{ No Work/HW(a) } \\
\hline Agri. Lab. & & 0.462 & 0.474 \\
\hline HW Plus Work & & $0.519^{* * *}$ & $0.018^{* *}$ \\
\hline \multicolumn{4}{|l|}{ Women's Education } \\
\hline \multicolumn{4}{|l|}{ Illiterate(a) } \\
\hline Primary & & $1.361^{* * *}$ & $1.181^{* * *}$ \\
\hline Sec. \& Higher & & $2.068^{* * *}$ & $1.941^{* * *}$ \\
\hline \multicolumn{4}{|l|}{ Wealth Status } \\
\hline \multicolumn{4}{|l|}{$\operatorname{Low}^{(a)}$} \\
\hline Middle & & $1.462^{* * *}$ & $1.01^{* * *}$ \\
\hline High & & $2.001^{* * *}$ & $2.501^{* *}$ \\
\hline \multicolumn{4}{|l|}{ Source of water } \\
\hline \multicolumn{4}{|l|}{ Tube well(a) } \\
\hline Standpipe & & $4.046^{* * *}$ & $3.386^{* *}$ \\
\hline Unprotected & & $.089^{* * *}$ & $.024^{* * *}$ \\
\hline \multicolumn{4}{|l|}{ Caste } \\
\hline \multicolumn{4}{|l|}{$\mathrm{SC}(\mathrm{a})$} \\
\hline OBC & & $4.75^{* * *}$ & $2.483^{* * *}$ \\
\hline
\end{tabular}


Table 5 (continued)

\begin{tabular}{|c|c|c|c|}
\hline Covariates & Model 1 & Model 2 & Model 3 \\
\hline Other & & $2.251^{*}$ & 2.206 \\
\hline _cons & $1.271^{*}$ & $0.081^{*}$ & $0.032^{* *}$ \\
\hline level of significance & 0.001 & 0.001 & 0.001 \\
\hline log likelihood_null & -457.429 & -457.429 & -457.429 \\
\hline log likelihood_full & -330.749 & -126.678 & -117.148 \\
\hline AIC & 667.497 & 287.357 & 272.297 \\
\hline BIC & 680.974 & 363.725 & 357.649 \\
\hline $\mathbf{N}$ & 660 & 660 & 660 \\
\hline
\end{tabular}

Note: (a): Reference Category; ${ }^{* * *}: p \leq 0.001 ;{ }^{* *}: p \leq 0.01 ; *: p \leq 0.05$; IFR: Intra-familial relations, WEGARMs: Women empowerment for gynecological and reproductive morbidities.

IFI \& WEGARMs: Interaction variable of IFR and WEGARMs

\section{Discussion and Conclusion}

The issue of GARMs is considered as "tabooed" topic and stressful for women. Earlier studies use the concept of familial relations to investigate the time spent together in context of child's human capital (Bryant \& Zick, 1996), solidarity, family harmony and well-being (Chuang, 2005), interaction and cohabitation as impediments of working activity (Smith, Downer, Lynch, \& Winter, 1969). The IFR and WEGARMs were found to be an endogenous predictor in terms of GARMs in a rural setting such as in Bihar, India. Therefore, advocating better IFR can be proved as effective determinants in combating maternal health. Additionally, women with high WEGARMs were more likely to utilize healthcare compared to those with low empowerment. There was higher likelihood that women with high empowerment status (OR: $1.55, p<0.001)$ are more concerned with healthcare than their counterpart women with low WEGARMs. Even within India, women empowerment varies with region. The women in southern India are more empowered compared to those in the north of the country (Dyson \& Moore, 1983; Sen, 1993). It is documented that lower empowerment and high fertility (Balk, 1994) results in increased health risk for women and the child (Mason, 1984). In Nalanda, the probability of women empowerment on GARMs was 0.18 as likely with an increase in parity by one unit from one/two to four or more. The women with parity one/two increases the WEGARMs by 0.68 percent while the parity four and more decreases not only the WEGARMs (by 1.5\% decrement) but IFR (by 2\% decrement) also. There is a negative relationship between higher number of children and WEGARMs among the women studied. The study support the findings that lower empowerment tends result in larger number of children (Abadian, 1996).

Several studies report that women's empowerment enables pregnancy care including in India (Bloom, Wypij, \& Gupta, 2001; Mistry, Galal, \& Lu, 2009). This study provides evidence to support the claim that economic status of the household is positively associated with the empowerment of women (Table 4). The estimates derived from simultaneous equation model suggests that, on average wealth status increases about 4 percent WEGARMs. This study suggests that a simultaneous association exists between the variables, where, WEGARMs has a positive and significant effect on IFR, and IFR has a positive and significant effect on WEGARMs (Wald test $=p<0.05$ ). This study argues that if the women are exposed to interact/discuss on her demand she tried to make the system convinced without paralyzing the inter-connectedness of familial relationship between her and the family in which she lives. The study confirms the view that if the family is a comfortable platform for discussion/interaction better decision can be arrived at, for a woman, particularly in a patriarchal society, then she can be more positively able to make the family/household convinced towards her decisions in healthcare perspective. For instance, the women with high 
IFR and WEGARMs are more likely to seek advice or treatment for her GARMs in Nalanda, rural Bihar. Additionally, the study provides the evidence that education and better socioeconomic status play a significant role in determining healthcare in GARMs and intra-familial relation thus WEGARMs among study population.

The limitations of this study are: the level of GARMs among women are based on self-reported morbidities, which may have been over-or under-reported. The estimate of healthcare utilization for GARMs was based on the definition of healthcare and included advice and treatment seeking. The findings should therefore be taken cautiously especially with regard to the restricted number of variables when analyzing "individual and household level characteristics".

\section{References}

Abadian, S. (1996). Women's autonomy and its impact on fertility. World Development, 24(12), 17931809. DOI: http://doi.org/http://dx.doi.org/10.1016/S0305-750X(96)00075-7

Adachi, T. (2008). Anemia in the field of obstetrics and gynecology. Nihon Rinsho. Japanese Journal of Clinical Medicine, 66(3), 548-552.

Askie, L. M., Duley, L., Henderson-Smart, D. J., \& Stewart, L. A. (2007). Antiplatelet agents for prevention of pre-eclampsia: a meta-analysis of individual patient data. The Lancet, 369(9575), 1791-1798.

Balk, D. (1994). Individual and community aspects of women's status and fertility in rural Bangladesh. Population Studies, 48(1), 21-45.

Bloom, S. S., Wypij, D., \& Gupta, M. Das. (2001). Dimensions of women's autonomy and the influence on maternal health care utilization in a north Indian city. Demography, 38(1), 67-78.

Bryant, W. K., \& Zick, C. D. (1996). An examination of parent-child shared time. Journal of Marriage and the Family, 227-237.

Census. (2011a). District Census Handbook, Series- 11, Part XII-B, Village and Town Wise Primary Census Abstract,Nalanda, Bihar, Census of India, 2011. New Delhi: Directorate of Census Operations, Registrar General \& Census Commissioner,India.

Census. (2011b). Primary Census Abstract, Table A-8, A-9, Series 11, Bihar, Census of India 2011. New Delhi: Directorate of Census Operations, Registrar General \& Census Commissioner,India.

Chang, P., Chen, P., Hsieh, C., \& Chiu, L. (2009). Risk factors on the menstrual cycle of healthy Taiwanese college nursing students. Australian and New Zealand Journal of Obstetrics and Gynaecology, 49(6), 689-694.

Chuang, Y. (2005). Effects of interaction pattern on family harmony and well-being: Test of interpersonal theory, Relational-Models theory, and Confucian ethics. Asian Journal of Social Psychology, 8(3), 272-291.

Collins, D., Jordan, C., \& Coleman, H. (2013). Brooks/Cole Empowerment Series: An Introduction to Family Social Work. Belmong, CA: Nelson Education.

Duley, L. (2009). The global impact of pre-eclampsia and eclampsia. In Seminars in perinatology (Vol. 33, pp. 130-137). Elsevier.

Dyson, T., \& Moore, M. (1983). On Kinship Structure, Female Autonomy, and Demographic Behaviour in India. Population and Development Review, 9(1), 35-50.

Earth, B., \& Sthapit, S. (2002). Uterine prolapse in rural Nepal: gender and human rights implications. A mandate for development. Culture, Health \& Sexuality, 4(3), 281-296.

Fujiwara, T., \& Nakata, R. (2010). Skipping breakfast is associated with reproductive dysfunction in post-adolescent female college students. Appetite, 55(3), 714-717.

Ganle, J. K., Obeng, B., Segbefia, A. Y., Mwinyuri, V., Yeboah, J. Y., \& Baatiema, L. (2015). How intrafamilial decision-making affects women's access to, and use of maternal healthcare services in Ghana: A qualitative study. BMC Pregnancy and Childbirth, 15(1). DOI: http://doi.org/10.1186/s12884-015-0590-4

Ganzevoort, W., Rep, A., Bonsel, G. J., Fetter, W. P. F., van Sonderen, L., De Vries, J. I. P., ... 
investigators, for the P. (2005). A randomised controlled trial comparing two temporising management strategies, one with and one without plasma volume expansion, for severe and early onset pre-eclampsia. BJOG: An International Journal of Obstetrics \& Gynaecology, 112(10), 1358-1368. DOI: http://doi.org/10.1111/j.1471-0528.2005.00687.x

Goldrath, M. H. (1995). Hysteroscopic endometrial ablation. Obstetrics and Gynecology Clinics of North America, 22(3), 559.

Greene, W. H. (1993). Econometric Analysis (2nd ed.). New York: Macmillan.

Houston, A. M., Abraham, A., Huang, Z., \& D'Angelo, L. J. (2006). Knowledge, attitudes, and consequences of menstrual health in urban adolescent females. Journal of Pediatric and Adolescent Gynecology, 19(4), 271-275.

IIPS. (2010). District Level Household and Facility Survey (DLHS-3), 2007-08. Mumbai: International Institute for Population Sciences \& Ministry of Health and Family Welfare, Govt. of India.

Kadir, R. A., Edlund, M., \& Von Mackensen, S. (2010). The impact of menstrual disorders on quality of life in women with inherited bleeding disorders. Haemophilia, 16(5), 832-839.

Khan, K. S., Wojdyla, D., Say, L., Gülmezoglu, A. M., \& Van Look, P. F. A. (2006). WHO analysis of causes of maternal death: a systematic review. The Lancet, 367(9516), 1066-1074.

Kishor, S., \& Subaiya, L. (2008). Understanding womens empowerment: a comparative analysis of Demographic and Health Surveys (DHS) data.

Lambert-Messerlian, G., Roberts, M. B., Urlacher, S. S., Ah-Ching, J., Viali, S., Urbanek, M., \& McGarvey, S. T. (2011). First assessment of menstrual cycle function and reproductive endocrine status in Samoan women. Human Reproduction , 26(9), 2518-2524. DOI: http:// doi.org/10.1093/humrep/der095

Mason, K. O. (1984). The status of women: A review of its relationships to fertility and mortality. The Population Sciences Division of the Rockefeller Foundation.

Mathias, S. D., Kuppermann, M., Liberman, R. F., Lipschutz, R. C., \& Steege, J. F. (1996). Chronic pelvic pain: prevalence, health-related quality of life, and economic correlates. Obstetrics \& Gynecology, 87(3), 321-327.

Mistry, R., Galal, O., \& Lu, M. (2009). Women's autonomy and pregnancy care in rural India: A contextual analysis. Social Science \& Medicine, 69(6), 926-933. DOI: http://doi.org/http://dx.doi.org/10.1016/j.socscimed.2009.07.008

ORGI. (2013). Annual Health Survey 2012-13 Factsheet, Bihar. New Delhi: Office of the Registrar General \& Census Commissioner, Ministry of Home Affairs, Government of India, India.

Pampel, F. C. (2000). Logistic regression: A primer. Thousand Oaks, CA: Sage Publications: Sage University Papers Series on Quantitative Applications in the Social Sciences, 07 -132.

Pro, C. S. C., \& Pro, C. S. M. (2016). Census and Survey Processing System, V 6.3. USA: U.S. Census Bureau and ICF Macro, U.S. Department of Commerce.

RGI. (2013). Special Bulletin on Maternal Mortality in India 2010-12. New Delhi, India: Sample Registration System, Office of Registrar General.

RGI. (2016). Sample Registration System Bulletin.

Sen, G. (1993). Paths to Fertility Decline: A Cross-country Analysis. In P. Bardhan \& M. Dattachandhri (Eds.), Development and change: Essays in honour of K.N. Raj (pp. 197-214). New Delhi, India: Oxford University Press.

Senarath, U., \& Gunawardena, N. S. (2009). Women's Autonomy in Decision Making for Health Care in South Asia. Asia Pacific Journal of Public Health, 21(2), 137-143. DOI: http:// doi.org/10.1177/1010539509331590

Smith, R. H., Downer, D. B., Lynch, M. T., \& Winter, M. (1969). Privacy and interaction within the family as related to dwelling space. Journal of Marriage and the Family, 559-566.

StataCorp, L. P. (2014). Stata 13. College Station: StataCorp LP.

Steegers, E. A. P., von Dadelszen, P., Duvekot, J. J., \& Pijnenborg, R. (2010). Pre-eclampsia. The Lancet, 376(9741), 631-644.

Tegerstedt, G., Miedel, A., Mæhle-Schmidt, M., Nyrén, O., \& Hammarström, M. (2006). Obstetric risk factors for symptomatic prolapse: a population-based approach. American Journal of Obstetrics and Gynecology, 194(1), 75-81.

Visser, W., \& Wallenburg, H. C. S. (1995). Maternal and perinatal outcome of temporizing management in 254 consecutive patients with severe pre-eclampsia remote from term. European Journal of Obstetrics \& Gynecology and Reproductive Biology, 63(2), 147-154. 
Vyver, E., Steinegger, C., \& Katzman, D. K. (2008). Eating disorders and menstrual dysfunction in adolescents. Annals of the New York Academy of Sciences, 1135(1), 253-264.

Walker, J. J., Greer, I., \& Calder, A. A. (1983). Treatment of acute pregnancy-related hypertension: labetalol and hydralazine compared. Postgraduate Medical Journal, 59, 168.

Walraven, G., Ekpo, G., Coleman, R., Scherf, C., Morison, L., \& Harlow, S. D. (2002). Menstrual disorders in rural Gambia. Studies in Family Planning, 33(3), 261-268.

White, D., Dynes, M., Rubardt, M., Sissoko, K., \& Stephenson, R. (2013). The influence of intra familial power on maternal health care in Mali: Perspectives of women, men and mothers-in-law. International Perspectives on Sexual and Reproductive Health, 39(2), 58-68. DOI: http://doi.org/10.1363/3905813

WHO. (2015). Trends in maternal mortality: 1990 to 2015. Estimates by WHO, UNICEF, UNFPA, World Bank Group and the United Nations Population Division. Switzerland: Geneva. 